\title{
Using injectable fillers for midface rejuvenation
}

\author{
Beatrice C. Go ${ }^{1,{ }^{*}}$, Ariel S. Frost ${ }^{1, \star},{ }^{\star}$ Oren Friedman ${ }^{2}$ \\ 'Department of Otorhinolaryngology, Hospital of University of Pennsylvania, Pennsylvania, PA 19104, USA. \\ ${ }^{2}$ Division of Facial Plastic \& Reconstructive Surgery, Department of Otorhinolaryngology, Hospital of University of Pennsylvania, \\ Pennsylvania, PA 19107, USA. \\ ${ }^{*}$ co-first authors.
}

Correspondence to: Dr. Oren Friedman, Department of Otorhinolaryngology, Hospital of University of Pennsylvania, 800 Walnut Street 18th Floor, Philadelphia, PA 19107, USA. E-mail: oren.friedman@pennmedicine.upenn.edu

How to cite this article: Go BC, Frost AS, Friedman O. Using injectable fillers for midface rejuvenation. Plast Aesthet Res 2021;8:39. https://dx.doi.org/10.20517/2347-9264.2021.35

Received: 17 Apr 2021 First Decision: 14 May 2021 Revised: 30 Jun 2021 Accepted: 6 Jul 2021 First online: 12 Jul 2021

Academic Editor: Wen-Guo Cui Copy Editor: Xi-Jun Chen Production Editor: Xi-Jun Chen

\begin{abstract}
Treatment aimed at preventing and reversing the facial aging process has grown in popularity. The aging midface is defined by classic deepening of the nasolabial folds, formation of marionette lines around the mouth, and significant atrophy of deep facial fat. While surgical options have been investigated with satisfactory and longlasting results, nonsurgical alternatives such as soft tissue fillers are a safe and effective strategy for facial rejuvenation. This review focuses on a variety of injectable fillers available for the treatment of the aging midface, including hyaluronic acid, calcium hydroxylapatite, poly-L-lactic acid, and polymethyl methacrylate. Mechanism of action, relevant anatomy, indications/contraindications, technique, and any evidence of efficacy and safety are described. The benefits of injectable fillers include reduced patient discomfort and shorter recovery times. Understanding the advantages and limitations of injectable fillers for midface augmentation can allow providers to counsel and treat patients seeking care appropriately.
\end{abstract}

Keywords: Hyaluronic acid, midface, nasolabial fold, mouth, aging, face, fillers

\section{INTRODUCTION}

Treating the aging face is a popular area of medicine, as every human is subject to the physiologic process of aging. Understanding the intrinsic physiological aging process is crucial for appropriate and individualized treatment selection. The age results in thinning of the epidermis, flattening of the dermal-epidermal 
junction, slower wound healing, and decreased cellular proliferation ${ }^{[1]}$. Reduced synthesis of collagen due to fibroblast aging and collagen damage change the overall composition of the $\operatorname{skin}^{[2,3]}$. Extrinsic aging, most commonly attributed to sun damage but also to tobacco use and gravity, can further exacerbate the appearance of dull, discolored, and wrinkled skin. Loss of subcutaneous volume from these mechanisms is the hallmark of the aging face. In the midface, deepening of the nasolabial folds and marionette lines around the mouth are attributed to the descent of nearby fat collections ${ }^{[4]}$. Additionally, significant atrophy of the deep facial fat that provides structural volume and support to the midface occurs with aging and has a profound impact on malar projection ${ }^{[5-7]}$.

A variety of treatment options for the aging face exist, and they include both surgical and nonsurgical alternatives. Since the introduction of facelift surgery in the early twentieth century, numerous developments have allowed for more satisfactory and long-lasting aesthetic results ${ }^{[8-10]}$. The modern-day rhytidectomy involves manipulation (i.e., plication, imbrication) of the superficial musculoaponeurotic system (SMAS). The deep-plane facelift has been touted as a procedure that better improves the nasolabial fold and malar fat pad $^{[11]}$. This technique involves sub-SMAS dissection with the simultaneous release of midfacial ligaments, allowing for repositioning of the malar fat pad. In exchange, however, patients are subject to greater tissue trauma, longer operative time, and increased risk of damage to the facial nerve ${ }^{[10]}$. Minimally invasive and noninvasive techniques such as the threadlift ${ }^{[12]}, \mathrm{S}$ - Lift $^{[13]}$, and minimal access cranial suspension lift ${ }^{[14]}$ are all attractive options, although the longevity of results is debated. No single approach to surgical intervention has been identified as ideal - patient need, patient choice, and surgeon preference tend to guide treatment selection ${ }^{[15,16]}$.

Soft tissue fillers represent the frontline of nonsurgical alternatives for facial rejuvenation. There are a plethora of options for dermal fillers with variations in material, permanency, viscosity (G'), elasticity (G'), and longevity. The Food and Drug Administration (FDA) has approved different injectables for specific areas of the face and disease processes, although off-label use to achieve facial rejuvenation is common practice. In the midface, injectable fillers appeal to diminish the appearance of nasojugal and nasolabial grooves and augment the malar region. The efficacy and safety profile of injectable fillers is well-reported, although the "temporary" nature of these products often necessitates multiple procedures. Though fortunately rare, intravascular infiltration and vascular compression by filler are concerning events and may lead to devastating complications ${ }^{[17]}$. Other nonsurgical options reported in the literature include intradermal botulinum toxin injection ${ }^{[18,19]}$, acoustic wave therapy ${ }^{[20]}$, laser ${ }^{[21]}$, and ultrasound ${ }^{[22]}$.

There are a variety of injectable fillers available for the treatment of the aging midface. The objective of this review is to describe the mechanism of action, indication, technique, and evidence of efficacy and safety. Understanding the advantages and limitations of injectable fillers for midface augmentation allows providers to appropriately counsel and treat patients.

\section{Hyaluronic acid}

The first soft-tissue fillers derived from bovine collagen in 1981 were immunogenic and caused inflammatory reactions ${ }^{[23]}$. The next generation of injectable fillers included hyaluronic acid (HA), an injectable extracellular matrix component. HA is a non-sulfated glycosaminoglycan composed of polymeric disaccharides with the unique property of forming stable structures in aqueous solution $\mathrm{s}^{[24]}$. The biological functions of HA throughout the body include lubrication of joint spaces and repair of tissue injury and wound healing ${ }^{[25]}$. In addition, dermal HA is diminished during the aging process, leading to loss of skin moisture, skin atrophy, and loss of elasticity ${ }^{[26]}$. Due to its molecular consistency across species, the minimal immunogenicity and relative ease of use have allowed HA fillers to be the most commonly used soft-tissue 
filler today ${ }^{[27]}$.

As a general guideline, injection of HA fillers is performed using 27- or 30-gauge needles along Hinderer's lines: two intersecting lines from the ala to the tragus and lateral canthus to lateral oral commissure ${ }^{[28]}$ [Figure 1]. The filler is then ideally placed in the upper outer quadrant. Volume replacement targeting specific midface areas is dependent on location and requires meticulous attention to ethnic differences in bony anatomy ${ }^{[29]}$. The upper cheek, lateral cheek, anterior cheek, and medial cheek are all potential injection sites, and injectors must take precautions to avoid the zygomatic neurovascular bundle, infraorbital artery and vein, and angular artery and vein ${ }^{[30]}$. Volume replacement in the lid-cheek junction ("tear trough") can be achieved with two or three injections along the nasojugal fold though care must be taken to avoid injury to vessels and orbital content ${ }^{[31]}$. There are two strategies to approach the submalar area: subcutaneous injection at numerous sites per side or a single medial subcutaneous injection using a fanning technique ${ }^{[32]}$. Providers should take care to avoid the facial vessels and parotid duct during both techniques. Volume replacement in the preauricular area can be accomplished with three to five superficial injection sites with care to avoid the parotid gland and transverse facial artery and vein ${ }^{[33]}$.

The first HA-based filler approved for use by the United States FDA was Restylane (Galderma, Fort Worth, TX) in $2003^{[34,35]}$. There are now many other products that differ in concentration, elastic modulus, and degree of cross-linking, including Juvederm (Allergan Inc., Pringy, France), which has been approved for a variety of indications, including correction of facial wrinkles and folds as well as lip and cheek augmentation. Additional modifications on these products, including a new product with increased crosslinking (Teosyal resilient HA, Geneva, Switzerland), have been created to help reduce degradation due to mechanical strain ${ }^{[36]}$. Multiple randomized controlled trials have demonstrated the efficacy of HA for agerelated midface volume deficit. In a multicenter, single-blinded, controlled study, $85.6 \%$ of subjects treated with Juvederm Voluma demonstrated a significant improvement of 1 point or more at 6 months follow-up on the Mid-Face Volume Deficit Scale, a validated blinded clinician score, compared with the control group $^{[37]}$. There were minimal adverse events, and more than half of the subjects reported lasting efficacy at 24 months. A follow-up study on patient satisfaction showed that nearly $93 \%$ and $79 \%$ of patients at 6 months and 2 years after treatment, respectively, noted improvement on the Global Aesthetic Improvement $\mathrm{Scale}^{[38]}$. In addition, patients reported looking 5 years younger at 6 months and 3 years younger at 2 years. Newer split-face trials are now comparing Cohesive Polydensified Matrix (CPM) (Merz Pharmaceuticals GmbH, Frankfurt am Main, Germany) with FDA-approved Vycross technology (Allergan Inc., Pringy, France), noting noninferior aesthetic results and more favorable safety and patient satisfaction profiles with $\mathrm{CPM}^{[3,40]}$.

\section{Calcium hydroxylapatite}

Calcium hydroxylapatite $(\mathrm{CaHa})$ is a unique compound with dual functionality as a replacement volumizer as well as a collagen biostimulator ${ }^{[41]}$. Due to its identical composition to human bone and teeth, CaHa is biodegradable, naturally resorbable, nontoxic, nonantigenic, and long-lasting, allowing for optimal biocompatibility and efficacy as a filler material ${ }^{[42]}$. CaHa's biostimulatory effects work by immediately creating volume while encouraging a fibroblastic response and acting as a scaffold for newly formed collagen after natural resorption and excretion ${ }^{[43-45]}$. CaHa has a wide range of indications beyond aesthetics, including correction of orthopedic ${ }^{[46]}$ and dental defects ${ }^{[47]}$ and vocal fold augmentation ${ }^{[48]}$. In 2006, Radiesse (Merz Pharmaceuticals GmbH, Frankfurt am Main, Germany) was FDA-approved for the correction of moderate to severe midface wrinkles and folds and lipoatrophy in patients with human immunodeficiency virus. Radiesse utilizes a 30:70 ratio mixture of $\mathrm{CaHa}$ microspheres to aqueous carrier gel and has been well studied in facial aesthetic medicine ${ }^{[42,49,50]}$. 


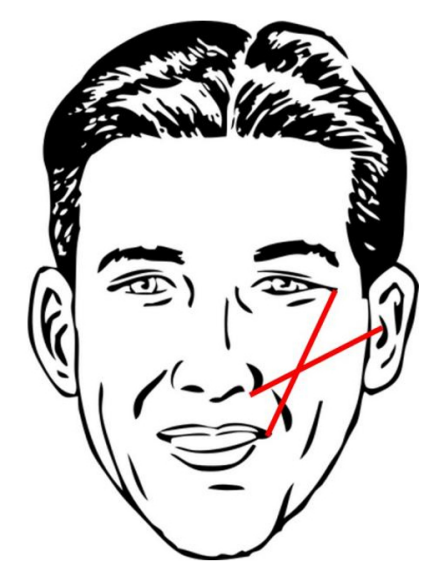

Figure 1. Hinderer's lines (two intersecting lines: ala/tragal, lateral canthal/commissure).

In the midface, restoration of the cheekbones allows for correction of specific creases and defects while providing volume to the malar and submalar regions. By augmenting the upper maxillary region, the shadowing effect seen with midface defects is ameliorated, resulting in a younger appearance ${ }^{[51]}$. CaHa can be placed using a similar technique to HA, though a larger bore needle or cannula is recommended due to the relative viscosity ${ }^{[52]}$. To achieve optimal aesthetic results, augmentation of the entire cheek and adjacent areas should be considered, not just the area of the defect ${ }^{[49]}$. Injection depth depends on location; superior to the alar-tragal line, CaHa should be injected superior to the periosteum, while subdermal injections are ideal for targeting areas inferior to the alar-tragal line ${ }^{[53]}$. After product placement, light massaging and molding of the filler are recommended to blend the injectable and reduce tissue edema and ecchymosis, thereby helping to achieve the desired outcome ${ }^{[42]}$.

There is a plethora of data supporting the long-term safety and efficacy of CaHa for facial soft-tissue augmentation. The first pivotal multi-center study comparing $\mathrm{CaHa}$ against human collagen in a randomized split-face trial reported significantly longer-lasting correction of nasolabial folds with less material used and fewer injections ${ }^{[54]}$. A follow-up safety study of 113 patients over 47 months showed only seven minor adverse events, including transient ecchymosis, submucosal nodules, and inflammation and edema ${ }^{[5]}$. Duration of action ranges from 12 to 18 months though long-term effectiveness of up to 30 months has been reported ${ }^{[56]}$. Despite these promising results, one systematic review reported that Radiesse was significantly more likely to result in intra-arterial complications and skin necrosis when compared with other facial fillers ${ }^{[5]}$. It is thought that the larger particle size of Radiesse increases the propensity of vascular compromise. Thus, the provider must remain vigilant to avoid vascular complications.

\section{Poly-L-lactic acid}

Poly-L-lactic acid (PLLA) is an absorbable, semi-permanent, biocompatible synthetic polymer that induces collagen synthesis, leading to volume restoration. After injection, PLLA particles stimulate an inflammatory response with tissue macrophages, leading to degradation into lactic acid and subsequently carbon dioxide and water ${ }^{[58]}$. This process promotes the formation of new type-I collagen as well as fibroblast activity, leading to gradual volume replacement ${ }^{[59]}$. The effect of PLLA stems from the natural host response rather than the immediate volume increase, thus leading to an extended duration of action from 12 to 24 months $s^{[60]}$. 
In the United States, Sculptra (Galderma, Fort Worth, TX) has been FDA-approved for facial lipoatrophy associated with HIV and more recently in 2009 for the correction of shallow to deep nasolabial folds and other facial wrinkles ${ }^{[17]}$. The product must be reconstituted with Sterile Water for Injection $(5 \mathrm{~mL})$ prior to injection to form a sterile suspension ${ }^{[1]}$. When approaching the midface, supraperiosteal injections over the zygoma, maxilla, and temples and subcutaneous injections in the submalar and preauricular areas are recommended $^{\left[{ }^{[2]}\right]}$. Consensus guidelines recommend 3-5 initial sessions for optimal results, with at least four weeks between sessions. Patients should be counseled that cosmetic effects have a gradual onset and can last two years or more ${ }^{[62]}$. Due to the slowly progressive bulking effects of PLLA, it is important to not overcorrect the treatment area with too much filler ${ }^{[63]}$.

Multiple retrospectives and prospective cohort studies have demonstrated the safety of injectable PLLA ${ }^{[64-67]}$. For example, a pivotal randomized, single-blinded, multicenter trial in 2010 compared the efficacy and safety of PLLA with human-derived collagen for nasolabial fold deficits ${ }^{[6]}$. Subjects receiving injectable PLLA had significantly improved average Wrinkle Assessment Scale scores at all-time points up to 25 months compared with the control group. Other similar trials have reported high provider and patient satisfaction with results ${ }^{[6,70]}$. Compared to HA fillers, PLLA was found to be noninferior in the correction of moderate to severe nasolabial folds and appeared to be superior to HA in patients less than 52 years of age $^{[7]}$. Main adverse effects include papules and nodules stemming from unequal distribution, inaccurate placement, and incorrect reconstitution ${ }^{[72]}$. As preparation and administration of PLLA have become increasingly standardized, however, the frequency of post-injection complications has also decreased ${ }^{[73]}$.

\section{Polymethyl methacrylate}

Polymethyl methacrylate (PMMA) is a synthetic, biologically compatible, inert, nonbiodegradable polymer originally used in dental and orthopedic procedures. Although a previous version (Artecoll, Canderm Pharma Inc, Canada) was marketed outside of the United States, newer generations of PMMA injectable fillers (ArteFill, later rebranded as Bellafill, Suneva Medical, San Diego, CA, USA) have been FDA approved for nasolabial fold augmentation since $2006^{[17,74]}$. These formulations contain PMMA microspheres, which are evenly distributed among denatured bovine collagen and lidocaine. Compared to other injectable filler materials, PMMA is a small, smooth permanent filler without electrical charge, thus preventing phagocytosis and degradation by macrophages ${ }^{[75]}$. Initial volume restoration is attributed to the collagen content in the filler though after this component is resorbed after 1 to 3 months, PMMA microspheres become permanently encapsulated with connective tissue and cells ${ }^{[76]}$. Due to the bovine collagen suspension, skin allergy testing must be conducted 2-4 weeks prior to injection, and double skin testing is often recommended to reduce the severity and incidence of allergic reactions ${ }^{[77]}$. On account of its permanent nature, the administration of PMMA requires careful attention to detail and placement. PMMA should be implanted intradermally, just superior to the dermis and subcutaneous layer ${ }^{[78]}$. The tunneling technique, or moving the needle back and forth beneath a wrinkle, allows for even distribution and layering of the product.

PMMA was initially introduced worldwide in the 1990s and became approved in 2006 after a multicenter randomized controlled trial of 251 subjects receiving Artecoll for a variety of facial wrinkles reported superior results to collagen dermal filler ${ }^{[78]}$. At 6 months follow-up, investigator and subject satisfaction ratings were higher at all injection sites, and significant augmentation was present at 12 months follow-up. After Artecoll, the next generation of PMMA was named Artefill, which boasted greater uniformity in size, surface contour, smoothness, and roundness ${ }^{[79]}$. Since then, PMMA has been repackaged as Bellafill, which offers a very favorable risk/benefit profile when administered properly. Short-term complications (tissue necrosis, infection) and long-term sequelae (granulomas, chronic inflammatory reaction) have been reported though they are fortunately rare occurrences ${ }^{[80]}$. A total of 1008 subjects receiving PMMA fillers for 
nasolabial folds was followed over five years, with biopsy-confirmed granulomas occurring in $1.7 \%{ }^{[81]}$. Almost all granulomas resolved with intralesional corticosteroid injections, and overall satisfaction rates remained high through the study period. In the event of nodules, skin changes, or contour irregularity, another study reported that surgical debulking of material could reduce the effects of these complications ${ }^{[82]}$. Long-term data also supports an excellent safety profile for this filler type. Surveillance data from 2007 to 2016 for more than half a million Bellafill syringes showed 11 total confirmed granulomas $(0.002 \% \text { or syringes sold })^{[79]}$.

\section{Fillers vs. surgery}

Although deep dermal fillers offer safe and excellent cosmetic results, it is important to consider which patients would likely benefit more from surgery. For those with more significant midface ptosis and facial volume loss, the more permanent and dramatic effects of rhytidectomy are more appealing. The main goals of the midface lift include effacement of the lower lid-cheek junction with volume restoration of the cheek and malar eminence ${ }^{[83]}$. Although a thorough discussion of surgical techniques is out of the scope of this review, providers must evaluate which patients would benefit from fillers, surgery, or a combination of both. During this conversation, differences in expected outcomes and recovery for the treatment options should be covered. If patients are willing to undergo general anesthesia and have significant soft tissue ptosis, most experts agree that a midface lift may be the more appropriate solution ${ }^{[83]}$. The addition of soft tissue fillers should be a separate discussion after the patient has had ample time to recover, allowing for the settling of the soft tissue.

Midface surgical options can confer longer-lasting results when compared with midface fillers. In a series of 157 patients undergoing a primary facelift at age $<50$, patients reported appearing significantly younger after facelift compared with after nonsurgical intervention (8 years $v s .4$ years, $P=0.048)^{[84]}$. Thirty-two percent of patients underwent an average of 7 rounds of injectable fillers prior to surgical intervention, with an average expenditure of $\$ 7000$ on nonsurgical procedures. Longevity of midface lift approaches has been reported, although most outcome measures are largely subjective, citing high patient satisfaction and quality of life scores at up to 5 years follow-up ${ }^{[85,86]}$. A recent study described a series of 143 patients undergoing an endoscopic transtemporal approach, reporting a significant, objective improvement in midfacial height that persisted for up to 15 years ${ }^{[8]}$. Despite these encouraging and lasting aesthetic results, no procedure is without its risks, which must be extensively discussed when counseling patients. The complications of midface lift surgery include asymmetry, infection, hematoma, facial and trigeminal neuropathy, and undesired scarring ${ }^{[88]}$.

\section{DISCUSSION}

Management of the midface with volume augmentation can be safely and effectively achieved with the use of soft tissue injectable fillers. The selection of filler is largely dependent on patient factors, including the severity of ptosis, degree of volume loss, age, cost, preference, and surgical candidacy ${ }^{[88]}$. From the provider's perspective, a detailed understanding of anatomy in the nasal region as well as proper technique is fundamental to minimizing the risk of complications and achieving the desired effect.

For decades, surgical rhytidectomy was established as the frontline procedure to enable patients to achieve predictable, customizable, and natural-looking results. However, the popularity of minimally invasive techniques has increased rapidly due to the introduction and wide acceptance of soft tissue fillers. Among the younger patient population that is not quite ready for a facelift, injectable fillers are an attractive, less permanent alternative to surgery. Compared to undergoing more invasive surgery, fillers offer the patient less discomfort and a shorter recovery time, making them very practical. Additionally, new and innovative 
advances to avoid anatomic danger zones and improve overall technique have led to safer injection practices ${ }^{[89-91]}$. Needle aspiration prior to injecting the filler has been reported to help prevent accidental intravascular injection ${ }^{[2]}$. With appropriate handling and adequate experience, injectable fillers are a safe and effective option for the aging midface.

The increasing popularity of facial fillers is well reflected in popular media and online news coverage. For example, a Google News search for articles on "facial fillers" from 2008 to 2017 reported coverage as 45\% positive, $30 \%$ neutral, and $25 \%$ negative ${ }^{[93]}$. While most media coverage at national and international levels was fairly positive, there was some concern with the regulation of facial fillers, a salient issue that may incite apprehension in some patients interested in the procedure. Additionally, nearly half of the papers discussed complications associated with the procedure despite the overall rarity of vascular injury and blindness ${ }^{[94,95]}$. As most cases of vision loss do not recover, and there is no consistent treatment for blindness, it is crucial for providers to understand the risks involved with the procedure and appropriately counsel patients ${ }^{[96]}$.

From an economic standpoint, the short-term cost of injectable fillers is another advantage for patients seeking minimally invasive treatment. However, a study by Biskupiak and Sclafani among several facial plastic surgeries and dermatology practices in New York City estimated that the total medical cost for surgical rhytidectomy was around $\$ 10,181^{[97]}$. When comparing this value to large-volume facial soft tissues assuming 90 months of the desired effect, the medical cost for surgery was the lowest cost option among the other treatments. When considering total costs, including workdays lost, ArteFill ( $\$ 11,151$ for 1 treatment) and Sculptra ( $\$ 14,850$ for 3.75 treatments) were less costly than surgical rhytidectomy $(\$ 15,181)$. This discrepancy was attributed to extra fees due to anesthesia, operating room, and overhead hospital costs, as well as the lengthier recovery period for surgery. However, it is important to consider that a rhytidectomy may ultimately be more cost-effective compared to patients undergoing large-volume filler augmentation over the course of several years.

There are multiple advances in filler technology to increase longevity while improving efficacy and safety profiles. For example, a new line of dermal fillers, called resilient hyaluronic acid (RHA) (Revance Therapeutics, Nashville, TN), was designed with a cross-linking method to mimic the function of native HA better. It is thought that these products (RHA 2, 3, 4) are able to adapt to facial movements to treat dynamic wrinkles and folds, a typical indication for neuromodulators ${ }^{[98]}$. Recently FDA approved for the correction of deep dynamic wrinkles, including the nasolabial folds; RHA 2 and 3 are indicated for injection into the mid-to-deep dermis, while RHA 4 is indicated for injection into the deep dermis to superficial subcutaneous tissue ${ }^{[99]}$. One split-face, randomized controlled trial on 90 subjects with moderate to severe nasolabial folds found at least equivalent efficacy and safety profiles with comparable fillers ${ }^{[100]}$. However, immediate and long-term satisfaction for both investigators and subjects favored RHA fillers with no reports of serious adverse events. At this time of writing, other dermal fillers expected to come to the United States market include Juvederm Volite (Allergan, Dublin, Ireland), the HA-based filler meant to improve skin quality, and ProfHilo (IBSA Nordic ApS, Denmark), another HA-based filler without any chemical cross-linking agents $^{[101,102]}$.

\section{CONCLUSION}

As a result of volume loss and fat atrophy, the aging midface is characterized by overall drooping of soft tissues and deepening of the nasolabial folds. Although surgical rhytidectomy is a long-lasting option for these patients, recent nonsurgical avenues, including filler injections, are becoming more popular due to reduced patient discomfort and recovery times. While filler selection may depend on patient preference and individual goals, providers must remain informed on the potential complications associated with midface 
augmentation and provide appropriate preprocedural counseling.

\section{DECLARATIONS}

\section{Authors' contributions}

Made substantial contributions to conception and design of the study, performed interpretation of data for the work, drafted the work, gave final approval of the version to be published, agreed to be accountable for all aspects of the work in ensuring that questions related to the accuracy or integrity of any part of the work are appropriately investigated and resolved: Go BC, Frost AS

Made substantial contributions to conception and design of the study, revised it critically for important intellectual content, gave final approval of the version to be published, agreed to be accountable for all aspects of the work in ensuring that questions related to the accuracy or integrity of any part of the work are appropriately investigated and resolved: Friedman $\mathrm{O}$

\section{Availability of data and materials}

Not applicable.

\section{Financial support and sponsorship}

None.

\section{Conflicts of interest}

All authors declared that there are no conflicts of interest.

\section{Ethical approval and consent to participate}

Not applicable.

\section{Consent for publication}

Not applicable.

\section{Copyright}

(c) The Author(s) 2021.

\section{REFERENCES}

1. Gilhar A, Ullmann Y, Karry R, et al. Ageing of human epidermis: the role of apoptosis, Fas and telomerase. Br $J$ Dermatol 2004;150:56-63. DOI PubMed

2. Varani J, Dame MK, Rittie L, et al. Decreased collagen production in chronologically aged skin: roles of age-dependent alteration in fibroblast function and defective mechanical stimulation. Am J Pathol 2006;168:1861-8. DOI PubMed PMC

3. Suwabe H, Serizawa A, Kajiwara H, Ohkido M, Tsutsumi Y. Degenerative processes of elastic fibers in sun-protected and sunexposed skin: immunoelectron microscopic observation of elastin, fibrillin-1, amyloid P component, lysozyme and alpha1antitrypsin. Pathol Int 1999;49:391-402. DOI PubMed

4. Gierloff M, Stöhring C, Buder T, Gassling V, Açil Y, Wiltfang J. Aging changes of the midfacial fat compartments: a computed tomographic study. Plast Reconstr Surg 2012;129:263-73. DOI PubMed

5. Boehm LM, Morgan A, Hettinger P, Matloub HS. Facial aging: a quantitative analysis of midface volume changes over 11 years. Plast Reconstr Surg 2021;147:319-27. DOI PubMed

6. Tower J, Seifert K, Paskhover B. Longitudinal analysis of superficial midfacial fat volumes over a 10-year period. Aesthetic Plast Surg 2018;42:995-1001. DOI PubMed

7. Rohrich RJ, Avashia YJ, Savetsky IL. Prediction of facial aging using the facial fat compartments. Plast Reconstr Surg 2021;147:38S-42S. DOI PubMed

8. Owsley JQ Jr, Zweifler M. Midface lift of the malar fat pad: technical advances. Plast Reconstr Surg 2002;110:674-85; discussion 686-7. DOI PubMed

9. De Cordier BC, de la Torre JI, Al-Hakeem MS, et al. Rejuvenation of the midface by elevating the malar fat pad: review of technique, cases, and complications. Plast Reconstr Surg 2002;110:1526-36; discussion 1537-40. DOI PubMed

10. Barrett DM, Gerecci D, Wang TD. Facelift controversies. Facial Plast Surg Clin North Am 2016;24:357-66. DOI PubMed

11. Hamra ST. The deep-plane rhytidectomy. Plast Reconstr Surg 1990;86:53-61; discussion 62-3. PubMed

12. Abraham RF, DeFatta RJ, Williams EF 3rd. Thread-lift for facial rejuvenation: assessment of long-term results. Arch Facial Plast 
Surg 2009;11:178-83. DOI PubMed

13. Saylan Z. The S-lift: less is more. Aesthet Surg J 1999;19:406-9. DOI

14. Tonnard P, Verpaele A, Monstrey S, et al. Minimal access cranial suspension lift: a modified S-lift. Plast Reconstr Surg 2002;109:2074-86. DOI PubMed

15. Chang S, Pusic A, Rohrich RJ. A systematic review of comparison of efficacy and complication rates among face-lift techniques. Plast Reconstr Surg 2011;127:423-33. DOI PubMed

16. Kim BJ, Choi JH, Lee Y. Development of facial rejuvenation procedures: thirty years of clinical experience with face lifts. Arch Plast Surg 2015;42:521-31. DOI PubMed PMC

17. General and Plastic Surgery Devices. FDA executive summary general issues panel meeting on dermal fillers. Available from: https://www.fda.gov/media/146870/download. [Last accessed on 2 Aug 2021].

18. Petchngaovilai C. Midface lifting with botulinum toxin: intradermal technique. J Cosmet Dermatol 2009;8:312-6. DOI PubMed

19. Chang SP, Tsai HH, Chen WY, Lee WR, Chen PL, Tsai TH. The wrinkles soothing effect on the middle and lower face by intradermal injection of botulinum toxin type A. Int J Dermatol 2008;47:1287-94. DOI PubMed

20. Kimura K, Tanaka Y. Facial tightening effects, following focused and radial acoustic wave therapy assessment, using a threedimensional digital imaging. Lasers Surg Med 2021;53:630-9. DOI PubMed PMC

21. Sasaki GH. Early clinical experience with the 1440-nm wavelength internal pulsed laser in facial rejuvenation: two-year follow-up. Clin Plast Surg 2012;39:409-17. DOI PubMed

22. Kwon HH, Choi SC, Park KH, Jung JY. A novel combination regimen with intense focused ultrasound and pressure- and dosecontrolled transcutaneous pneumatic injection of hypertonic glucose solution for lifting and tightening of the aging face. $J$ Cosmet Dermatol 2018;17:373-9. DOI PubMed

23. Ozgentaş HE, Pindur A, Spira M, Liu B, Shenaq S. A comparison of soft-tissue substitutes. Ann Plast Surg 1994;33:171-7. DOI PubMed

24. Papakonstantinou E, Roth M, Karakiulakis G. Hyaluronic acid: a key molecule in skin aging. Dermatoendocrinol 2012;4:253-8. DOI PubMed PMC

25. Toole BP. Hyaluronan: from extracellular glue to pericellular cue. Nat Rev Cancer 2004;4:528-39. DOI PubMed

26. Meyer LJ, Stern R. Age-dependent changes of hyaluronan in human skin. J Invest Dermatol 1994;102:385-9. DOI PubMed

27. Kim JE, Sykes JM. Hyaluronic acid fillers: history and overview. Facial Plast Surg 2011;27:523-8. DOI PubMed

28. Hinderer UT. Malar implants for improvement of the facial appearance. Plast Reconstr Surg 1975;56:157-65. DOI PubMed

29. Oranges CM, Gohritz A, Haug M, Harder Y, Schaefer DJ. Universal and ethnic-specific considerations on facial rejuvenation: where do you inject your fillers? Plast Reconstr Surg Glob Open 2016;4:e842. DOI PubMed PMC

30. Maio M, DeBoulle K, Braz A, Rohrich RJ; Alliance for the Future of Aesthetics Consensus Committee. Facial assessment and injection guide for botulinum toxin and injectable hyaluronic acid fillers: focus on the midface. Plast Reconstr Surg 2017;140:540e50e. DOI PubMed

31. Raspaldo H, Gassia V, Niforos FR, Michaud T. Global, 3-dimensional approach to natural rejuvenation: part 1 - recommendations for volume restoration and the periocular area. J Cosmet Dermatol 2012;11:279-89. DOI PubMed

32. Arsiwala SZ. Simplifying injectables for volumetric rejuvenation of face. J Cutan Aesthet Surg 2018;11:51-9. DOI PubMed PMC

33. Salti G, Rauso R. Facial rejuvenation with fillers: the dual plane technique. J Cutan Aesthet Surg 2015;8:127-33. DOI PubMed PMC

34. Tan M, Kontis TC. Midface volumization with injectable fillers. Facial Plast Surg Clin North Am 2015;23:233-42. DOI PubMed

35. Weiss RA, Moradi A, Bank D, et al. Effectiveness and safety of large gel particle hyaluronic acid with lidocaine for correction of midface volume deficit or contour deficiency. Dermatol Surg 2016;42:699-709. DOI PubMed

36. Monheit G, Kaufman-Janette J, Joseph JH, Shamban A, Dover JS, Smith S. Efficacy and safety of two resilient hyaluronic acid fillers in the treatment of moderate-to-severenasolabial folds: a 64-week, prospective, multicenter, controlled, randomized, double-blinded, and within-subject study. Dermatol Surg 2020;46:1521-9. DOI PubMed

37. Jones D, Murphy DK. Volumizing hyaluronic acid filler for midface volume deficit: 2-year results from a pivotal single-blind randomized controlled study. Dermatol Surg 2013;39:1602-12. DOI PubMed

38. Few J, Cox SE, Paradkar-Mitragotri D, Murphy DK. A multicenter, single-blind randomized, controlled study of a volumizing hyaluronic acid filler for midface volume deficit: patient-reported outcomes at 2 years. Aesthet Surg J 2015;35:589-99. DOI PubMed PMC

39. Kerscher M, Agsten K, Kravtsov M, Prager W. Effectiveness evaluation of two volumizing hyaluronic acid dermal fillers in a controlled, randomized, double-blind, split-face clinical study. Clin Cosmet Investig Dermatol 2017;10:239-47. DOI PubMed PMC

40. Prager W, Agsten K, Kerscher M. Patient-reported outcomes following split-face injection of 2 volumizing fillers in the upper cheeks. Plast Reconstr Surg Glob Open 2017;5:e1412. DOI PubMed PMC

41. Ahn MS. Calcium hydroxylapatite: Radiesse. Facial Plast Surg Clin North Am 2007;15:85-90, vii. DOI PubMed

42. Jacovella PF. Use of calcium hydroxylapatite (Radiesse $($ ) for facial augmentation. Clin Interv Aging 2008;3:161-74. DOI

43. Marmur ES, Phelps R, Goldberg DJ. Clinical, histologic and electron microscopic findings after injection of a calcium hydroxylapatite filler. J Cosmet Laser Ther 2004;6:223-6. DOI PubMed

44. Yutskovskaya Y, Kogan E, Leshunov E. A randomized, split-face, histomorphologic study comparing a volumetric calcium hydroxylapatite and a hyaluronic acid-based dermal filler. J Drugs Dermatol JDD 2014;13:1047-52. PubMed

45. Berlin AL, Hussain M, Goldberg DJ. Calcium hydroxylapatite filler for facial rejuvenation: a histologic and immunohistochemical analysis. Dermatol Surg 2008;34 Suppl 1:S64-7. DOI PubMed 
46. Berri N, Fares J, Fares Y. Polyethylene oxide and silicon-substituted hydroxyapatite composite: a biomaterial for hard tissue engineering in orthopedic and spine surgery. Adv Biomed Res 2018;7:117. DOI PubMed PMC

47. Pajor K, Pajchel L, Kolmas J. Hydroxyapatite and fluorapatite in conservative dentistry and oral implantology-a review. Materials (Basel) 2019;12:2683. DOI PubMed PMC

48. Cohen JT, Benyamini L. Voice outcome after vocal fold injection augmentation with carboxymethyl cellulose versus calcium hydroxyapatite. J Laryngol Otol 2020;134:263-9. DOI PubMed

49. Graivier MH, Bass LS, Busso M, Jasin ME, Narins RS, Tzikas TL. Calcium hydroxylapatite (Radiesse) for correction of the mid- and lower face: consensus recommendations. Plast Reconstr Surg 2007;120:55S-66S. DOI PubMed

50. Jansen DA, Graivier MH. Evaluation of a calcium hydroxylapatite-based implant (Radiesse) for facial soft-tissue augmentation. Plast Reconstr Surg 2006;118:22S-30S, discussion 31S-3S. DOI PubMed

51. Fitzgerald R, Carqueville J, Yang PT. An approach to structural facial rejuvenation with fillers in women. Int $J$ Womens Dermatol 2019;5:52-67. DOI PubMed PMC

52. Palermo EC, Anzai A. Calcium hydroxyapatite for face. In: Costa AD, editor. Minimally invasive aesthetic procedures. Cham: Springer International Publishing; 2020. p. 487-97. DOI PubMed PMC

53. Loghem JV, Yutskovskaya YA, Werschler WP. Calcium hydroxylapatite: over a decade of clinical experience. J Clin Aesthetic Dermatol 2015;8:38. PubMed PMC

54. Smith S, Busso M, McClaren M, Bass LS. A randomized, bilateral, prospective comparison of calcium hydroxylapatite microspheres versus human-based collagen for the correction of nasolabial folds. Dermatol Surg 2007;33 Suppl 2:S112-21; discussion S121. DOI PubMed

55. Sadick NS, Katz BE, Roy D. A multicenter, 47-month study of safety and efficacy of calcium hydroxylapatite for soft tissue augmentation of nasolabial folds and other areas of the face. Dermatol Surg 2007;33 Suppl 2:S122-6; discussion S126-7. DOI PubMed

56. Bass LS, Smith S, Busso M, McClaren M. Calcium hydroxylapatite (Radiesse) for treatment of nasolabial folds: long-term safety and efficacy results. Aesthet Surg J 2010;30:235-8. DOI PubMed

57. Rayess HM, Svider PF, Hanba C, et al. A cross-sectional analysis of adverse events and litigation for injectable fillers. JAMA Facial Plast Surg 2018;20:207-14. DOI PubMed PMC

58. Sickles CK, Nassereddin A, Gross GP. Poly-L-lactic acid. In: StatPearls. StatPearls Publishing; 2020. PubMed

59. Cabral LRB, Teixeira LN, Gimenez RP, et al. Effect of hyaluronic acid and poly-L-lactic acid dermal fillers on collagen synthesis: an in vitro and in vivo Study. Clin Cosmet Investig Dermatol 2020;13:701-10. DOI PubMed PMC

60. Rotunda AM, Narins RS. Poly-L-lactic acid: a new dimension in soft tissue augmentation. Dermatol Ther 2006;19:151-8. DOI PubMed

61. Galderma. Sculptra aesthetic injectable poly-L-lactic acid. 2020. Available from: https://www.galderma.com/us/sites/g/files/jcdfhc341/files/2020-11/782347\%20Sculptra\%20Aesthetic\%20IFU.pdf. [Last accessed on 2 Aug 2020].

62. Vleggaar D, Fitzgerald R, Lorenc ZP, et al. Consensus recommendations on the use of injectable poly-L-lactic acid for facial and nonfacial volumization. J Drugs Dermatol JDD 2014;13:s44-51. PubMed

63. Bartus C, William Hanke C, Daro-Kaftan E. A decade of experience with injectable poly-L-lactic acid: a focus on safety. Dermatol Surg 2013;39:698-705. DOI PubMed

64. Lowe NJ, Maxwell CA, Lowe P, Shah A, Patnaik R. Injectable poly-1-lactic acid: 3 years of aesthetic experience. Dermatol Surg 2009;35 Suppl 1:344-9. DOI PubMed

65. Bauer U, Graivier MH. Optimizing injectable poly-L-lactic acid administration for soft tissue augmentation: the rationale for three treatment sessions. Can J Plast Surg J Can Chir Plast 2011;19:e22-7. PubMed PMC

66. Butterwick K, Lowe NJ. Injectable poly-L-lactic acid for cosmetic enhancement: learning from the European experience. J Am Acad Dermatol 2009;61:281-93. DOI PubMed

67. Salles AG, Lotierzo PH, Gimenez R, Camargo CP, Ferreira MC. Evaluation of the poly-L-lactic acid implant for treatment of the nasolabial fold: 3-year follow-up evaluation. Aesthetic Plast Surg 2008;32:753-6. DOI PubMed

68. Narins RS, Baumann L, Brandt FS, et al. A randomized study of the efficacy and safety of injectable poly-L-lactic acid versus human-based collagen implant in the treatment of nasolabial fold wrinkles. J Am Acad Dermatol 2010;62:448-62. DOI PubMed

69. Brandt FS, Cazzaniga A, Baumann L, et al. Investigator global evaluations of efficacy of injectable poly-L-lactic acid versus human collagen in the correction of nasolabial fold wrinkles. Aesthet Surg J2011;31:521-8. DOI PubMed

70. Brown SA, Rohrich RJ, Baumann L, et al. Subject global evaluation and subject satisfaction using injectable poly-L-lactic acid versus human collagen for the correction of nasolabial fold wrinkles. Plast Reconstr Surg 2011;127:1684-92. DOI PubMed

71. Hyun MY, Lee Y, No YA, et al. Efficacy and safety of injection with poly-L-lactic acid compared with hyaluronic acid for correction of nasolabial fold: a randomized, evaluator-blinded, comparative study. Clin Exp Dermatol 2015;40:129-35. DOI PubMed

72. Narins RS. Minimizing adverse events associated with poly-L-lactic acid injection. Dermatol Surg 2008;34 Suppl 1:S100-4. DOI PubMed

73. Haneke E. Managing complications of fillers: rare and not-so-rare. J Cutan Aesthet Surg 2015;8:198-210. DOI PubMed PMC

74. Solomon P, Sklar M, Zener R. Facial soft tissue augmentation with Artecoll®: A review of eight years of clinical experience in 153 patients. Can J Plast Surg 2012;20:28-32. DOI PubMed PMC

75. Morhenn VB, Lemperle G, Gallo RL. Phagocytosis of different particulate dermal filler substances by human macrophages and skin cells. Dermatol Surg 2002;28:484-90. DOI PubMed

76. Lemperle G, Romano JJ, Busso M. Soft tissue augmentation with artecoll: 10-year history, indications, techniques, and 
complications. Dermatol Surg 2003;29:573-87; discussion 587. DOI PubMed

77. Elson ML. The role of skin testing in the use of collagen injectable materials. J Dermatol Surg Oncol 1989;15:301-3. DOI PubMed

78. Cohen SR, Holmes RE. Artecoll: a long-lasting injectable wrinkle filler material: report of a controlled, randomized, multicenter clinical trial of 251 subjects. Plast Reconstr Surg 2004;114:964-76; discussion 977-9. DOI PubMed

79. Gold MH, Sadick NS. Optimizing outcomes with polymethylmethacrylate fillers. J Cosmet Dermatol 2018;17:298-304. DOI PubMed

80. Salles AG, Lotierzo PH, Gemperli R, et al. Complications after polymethylmethacrylate injections: report of 32 cases. Plast Reconstr Surg 2008;121:1811-20. DOI PubMed

81. Cohen S, Dover J, Monheit G, et al. Five-year safety and satisfaction study of PMMA-collagen in the correction of nasolabial folds. Dermatol Surg 2015;41 Suppl 1:S302-13. DOI PubMed

82. Limongi RM, Tao J, Borba A, et al. Complications and management of polymethylmethacrylate (PMMA) injections to the midface. Aesthet Surg J 2016;36:132-5. DOI PubMed

83. Keller G, Quatela VC, Antunes MB, Sykes JM, Magill CK, Seth R. Midface lift: panel discussion. Facial Plast Surg Clin North Am 2014;22:119-37. DOI PubMed

84. Jacono AA, Malone MH, Lavin TJ. Nonsurgical facial rejuvenation procedures in patients under 50 prior to undergoing facelift: habits, costs, and results. Aesthet Surg J 2017;37:448-53. DOI PubMed

85. Ransom ER, Stong BC, Jacono AA. Persistent improvement in lower eyelid-cheek contour after a transtemporal midface lift. Aesthetic Plast Surg 2012;36:1277-82. DOI PubMed

86. Pascali M, Quarato D, Bocchini I, Cervelli V. Midface-lift patient satisfaction: a 5-year follow-up study. Indian J Plast Surg 2016;49:329-35. DOI PubMed PMC

87. Shtraks JP, Fundakowski C, Yu D, et al. Investigation of the longevity of the endoscopic midface lift. JAMA Facial Plast Surg 2019;21:535-41. DOI PubMed PMC

88. Pontius AT, Chaiet SR, Williams EF 3rd. Midface injectable fillers: have they replaced midface surgery? Facial Plast Surg Clin North Am 2013;21:229-39. DOI PubMed

89. Hufschmidt K, Bronsard N, Foissac R, et al. The infraorbital artery: clinical relevance in esthetic medicine and identification of danger zones of the midface. J Plast Reconstr Aesthet Surg 2019;72:131-6. DOI PubMed

90. Khan TT, Colon-Acevedo B, Mettu P, DeLorenzi C, Woodward JA. An anatomical analysis of the supratrochlear artery: considerations in facial filler ilnjections and preventing vision loss. Aesthet Surg J 2017;37:203-8. DOI PubMed

91. Gatherwright JR, Brown MS, Katira KM, Rowe DJ. Three-dimensional changes in the midface following malar calcium hydroxyapatite injection in a cadaver model. Aesthet Surg J 2015;35:NP169-75. DOI PubMed

92. Casabona G. Blood Aspiration Test for cosmetic fillers to prevent accidental intravascular injection in the face. Dermatol Surg 2015;41:841-7. DOI PubMed

93. Hojjat H, Raad R, Lucas J, et al. Public perception of facial fillers. Facial Plast Surg 2019;35:204-9. DOI PubMed

94. DeLorenzi C. Complications of injectable fillers, part 2: vascular complications. Aesthet Surg J 2014;34:584-600. DOI PubMed

95. Sito G, Manzoni V, Sommariva R. Vascular complications after facial filler injection: a literature review and meta-analysis. $J$ Clin Aesthetic Dermatol 2019;12:E65-72. PubMed PMC

96. Beleznay K, Carruthers JD, Humphrey S, Jones D. Avoiding and treating blindness from fillers: a review of the world literature. Dermatol Surg 2015;41:1097-117. DOI PubMed

97. Biskupiak J, Sclafani AP. Economic analysis of "liquid" versus surgical face-lift: are large-volume facial soft tissue filler injection treatments a viable alternative to rhytidectomy? Facial Plast Surg 2010;26:296-302. DOI PubMed

98. Kaufman-Janette J, Taylor SC, Cox SE, Weinkle SH, Smith S, Kinney BM. Efficacy and safety of a new resilient hyaluronic acid dermal filler, in the correction of moderate-to-severe nasolabial folds: a 64-week, prospective, multicenter, controlled, randomized, double-blind and within-subject study. J Cosmet Dermatol 2019;18:1244-53. DOI PubMed PMC

99. Food and Drug Administration: Summary of safety and effectiveness data (SSED). Available from: https://www.accessdata.fda.gov/cdrh_docs/pdf17/P170002B.pdf. [Last accessed on 8 Aug 2021].

100. Rzany B, Converset-Viethel S, Hartmann M, et al. Efficacy and safety of 3 new resilient hyaluronic acid fillers, crosslinked with decreased BDDE, for the treatment of dynamic wrinkles: results of an 18-month, randomized controlled trial versus already available comparators. Dermatol Surg 2019;45:1304-14. DOI PubMed

101. Niforos F, Ogilvie P, Cavallini M, et al. VYC-12 injectable gel is safe and effective for improvement of facial skin topography: a prospective study. Clin Cosmet Investig Dermatol 2019;12:791-8. DOI PubMed PMC

102. Sparavigna A, Tenconi B. Efficacy and tolerance of an injectable medical device containing stable hybrid cooperative complexes of high- and low-molecular-weight hyaluronic acid: a monocentric 16 weeks open-label evaluation. Clin Cosmet Investig Dermatol 2016;9:297-305. DOI PubMed PMC 